\title{
NGR-tagged nano-gold: A new CD13-selective carrier for cytokine delivery to tumors
}

\author{
Flavio Curnis ${ }^{1}(\varangle)$, Martina Fiocchi ${ }^{1}$, Angelina Sacchi ${ }^{1}$, Alessandro Gori ${ }^{2}$, Anna Gasparri ${ }^{1}$, and Angelo Corti ${ }^{1,3}(\varangle)$ \\ ${ }^{1}$ Division of Experimental Oncology, IRCCS San Raffaele Scientific Institute, Milan 20132, Italy \\ ${ }^{2}$ Istituto di Chimica del Riconoscimento Molecolare, CNR, Milan 20131, Italy \\ ${ }^{3}$ Vita Salute San Raffaele University, Milan 20132, Italy
}

\author{
Received: 21 October 2015 \\ Revised: 26 January 2016 \\ Accepted: 28 January 2016 \\ (C) The author(s) 2016. This \\ article is published with open \\ access at Springerlink.com

\section{KEYWORDS} \\ Asn-Gly-Arg (NGR), \\ isoAsp-Gly-Arg (isoDGR), \\ CD13, \\ integrin, \\ tumor necrosis factor, \\ albumin, \\ gold nanoparticles
}

\begin{abstract}
Colloidal gold $(\mathrm{Au})$, a well-tolerated nanomaterial, is currently exploited for several applications in nanomedicine. We show that gold nanoparticles tagged with a novel tumor-homing peptide containing Asn-Gly-Arg (NGR), a ligand of CD13 expressed by the tumor neovasculature, can be exploited as carriers for cytokine delivery to tumors. Biochemical and functional studies showed that the NGR molecular scaffold/linker used for gold functionalization is critical for CD13 recognition. Using fibrosarcoma-bearing mice, NGR-tagged nanodrugs could deliver extremely low, yet pharmacologically active doses of tumor necrosis factor (TNF), an anticancer cytokine, to tumors with no evidence of toxicity. Mechanistic studies confirmed that CD13 targeting was a primary mechanism of drug delivery and excluded a major role of integrin targeting consequent to NGR deamidation, a degradation reaction that generates the isoAsp-Gly-Arg (isoDGR) integrin ligand. NGR-tagged gold nanoparticles can be used, in principle, as a novel platform for single- or multi-cytokine delivery to tumor endothelial cells for cancer therapy.
\end{abstract}

\section{Introduction}

The efficacy of cytokines in cancer therapy is often limited by their toxicity and counter-regulatory mechanisms. For example, the anti-tumor activity of tumor necrosis factor-alpha (TNF), an inflammatory cytokine with potent anti-tumor activity, is limited by a prohibitive systemic toxicity and by the release of soluble TNF-receptors into the circulation that inhibit its anticancer activity [1]. We have previously shown that these limitations can be overcome, at least in the cases of TNF and interferon (IFN)-gamma, by administering extremely low amounts of cytokines fused to tumor vasculature-homing ligands, a strategy that enables "active" targeted delivery of pharmacologically relevant doses of cytokines to tumors [2-4]. One of these products, NGR-TNF, which consists of TNF fused to a tumor-homing disulfide-bridged peptide containing Asn-Gly-Arg (NGR), is now under investigation as an anticancer drug in phase II and III

Address correspondence to Flavio Curnis, curnis.flavio@hsr.it; Angelo Corti, corti.angelo@hsr.it 
clinical studies, with evidence of activity and good tolerability [1, 2, 5-7].

The therapeutic index of cytokines can also be increased by an alternative strategy based on cytokine coupling with colloidal gold, a well-tolerated nanomaterial currently exploited for several applications in the field of nanomedicine $[8,9]$. For example, the therapeutic index of TNF is significantly increased by coupling with $27-\mathrm{nm}$ gold nanoparticles [10], a formulation that is being tested in cancer patients, with evidence of improved efficacy [11, 12]. The improved activity of nanogold-based drugs is likely dependent on "passive" targeting mechanisms owing to abnormally leaky vasculature in tumors, which leads to enhanced permeability and drug retention in neoplastic tissues [10].

The combination of "active" and "passive" targeting mechanisms might represent an efficient strategy for improving the delivery of cytokines to the tumor vasculature, thereby reducing the cytokine dose necessary to induce pharmacological effects and minimizing the activation of counter-regulatory mechanisms. This could be achieved, in principle, by coupling gold nanoparticles with tumor-homing ligands selective for receptors that are overexpressed by tumor cells and/or vasculature.

Disulfide-bridged NGR peptides (e.g., CNGRC) could be exploited for this purpose; they have been successfully used to deliver TNF, IFN-gamma, and IFN-alpha-2a to tumors $[2,3,13]$ owing to their ability to recognize an aminopeptidase-N (CD13) form expressed by tumor vessels [14-16]. However, the sulfur atoms of these peptides may bind to gold, thereby altering or hindering the NGR structure. Thus, an alternative molecular scaffold of NGR is necessary. In this regard, a relevant issue is the potential impact of the scaffold on NGR stability and function. Indeed, consistent experimental evidence suggests that the NGR scaffold crucially affects asparagine $(\mathrm{N})$ deamidation, a spontaneous degradation reaction that leads to the formation of aspartate (D) and isoaspartate (isoD). Remarkably, this reaction, which occurs in an unusually rapid manner in NGR peptides (e.g., the half-life of asparagine in CNGRC is 3-4 h) [17, 18], causes a change in function, as the transition from NGR to isoAsp-Gly-Arg (isoDGR) (but not to DGR) is accompanied by receptor switching from CD13 to integrins
[17-20]. Biochemical studies, NMR structure analyses, and integrin-docking experiments have shown that isoDGR, but not NGR or DGR, can fit into the RGDbinding pocket of $\alpha \mathrm{v} \beta 3$, an integrin that is overexpressed in tumor vessels, recapitulating not only the canonical RGD/integrin contacts, but also establishing additional polar interactions [21]. Remarkably, isoDGR embedded in different molecular scaffolds have markedly different affinities for $\alpha v \beta 3$ and can bind other integrins, such as $\alpha v \beta 5, \alpha v \beta 6, \alpha v \beta 8$, and $\alpha 5 \beta 1$ $[17,18,21-23]$. Even the linker used for peptide coupling to proteins can affect integrin binding [24]. Thus, the molecular scaffold and the linker of NGR might be crucial for peptide/gold interactions, peptide stability, NGR conformation, and CD13 recognition, as well as for the receptor binding properties of the NGR degradation products, with potentially important pharmacological and toxicological implications.

Accordingly, we prepared various TNF/gold-based nanodrugs functionalized with peptides containing NGR (or its degradation product isoDGR) embedded in different scaffolds and characterized their functional properties and their therapeutic activity in experimental models. We show that gold nanoparticles tagged with a novel head-to-tail cyclic NGR peptide can be used as carriers for delivering extremely low doses of TNF to tumors, with evidence of activity. Furthermore, we provide evidence that the mechanism of action is primarily mediated by CD13 targeting, and not by integrin targeting consequent to isoDGR formation.

\section{Results}

\subsection{Preparation and characterization of NGR and IsoDGR peptides}

We prepared new hexa- and epta-peptides (head-totail cyclized), called N1, N3, N4, and N5, containing NGR and a Cys residue with a free thiol group that enables peptide coupling to proteins or to nanoparticles by using maleimide-containing bifunctional cross-linkers (see Fig. 1 for a schematic representation). In parallel, we prepared two disulfide-bridged peptides (called NGR-2C and NGR-2C(Y)), and two isoDGR peptides corresponding to the main deamidation products of N1 and N3 (called Iso1 and Iso3) (Fig. 1), previously described $[17,18,24]$, which can be used 


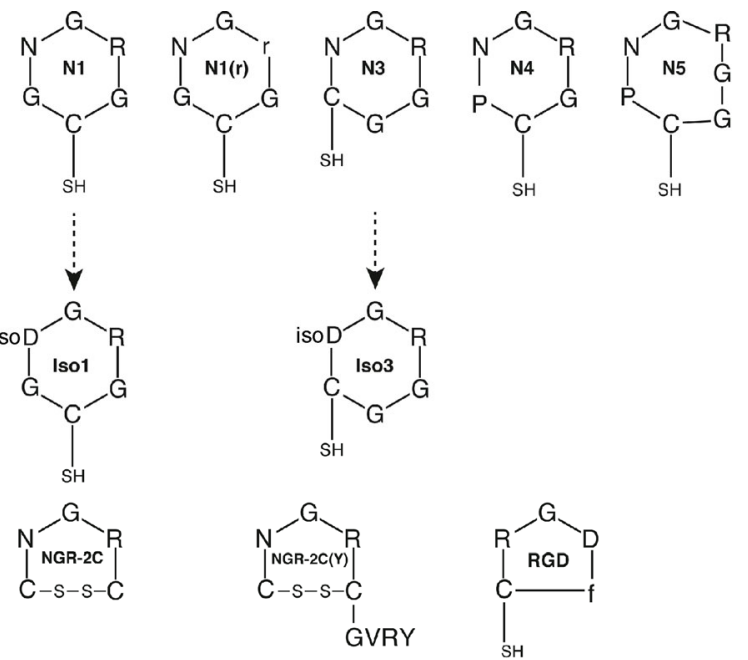

Figure 1 Schematic representation of NGR, isoDGR, and RGD peptides with different molecular scaffolds prepared by chemical synthesis. Amino acids are represented with the single letter code; $\mathrm{SH}$, free thiol group; isoD, isoaspartate; $\mathrm{r}$, D-arginine; f, D-phenylalanine. Peptide codes are reported within each structure. Arrows indicate the isoDGR deamidation products of N1 and N3.

as positive controls in CD13 and integrin binding studies. Other control peptides, including a mutated form of N1 with D-Arg in place of L-Arg (called N1(r)) and a peptide with RGD in place of NGR (CRGDf, called RGD), all cyclic and with a free thiol, were also prepared (Fig. 1). A mass spectrometry analysis of each product showed molecular masses consistent with the expected values (Table S1 in the Electronic Supplementary Material (ESM)).

The capability of NGR peptides to recognize CD13 was analyzed by enzyme inhibition and competitive binding assays. We observed that the peptides N1 and N3 were the most efficient inhibitors and binders (Fig. 2(a) and Table S2 and Fig. S1 in the ESM). Noteworthy, while N3 inhibited CD13 with potency similar to that of NGR-2C(Y), a reference peptide, $\mathrm{N} 1$ was about 5-6-fold more efficient, pointing to an important role of the NGR molecular scaffold in CD13 recognition. N4, N5, N1(r), and RGD caused little or no inhibition (Figs. 2(a) and 2(b)). Based on a steady-state enzyme kinetic analysis in the presence of various amounts of substrate and inhibitors, N1, N3, and NGR-2C affected the Michaelis constant $\left(K_{\mathrm{m}}\right)$, but not the maximum velocity $\left(V_{\max }\right)$ (Fig. 2(c)). The data were consistent with the competitive inhibition model (N1, $K_{\mathrm{i}}=12.4 \pm 5.4 \mu \mathrm{M} ; \mathrm{N} 3, K_{\mathrm{i}}=81.3 \pm 12.1 ; \mathrm{NGR}-2 \mathrm{C}, K_{\mathrm{i}}=$ $134 \pm 28$ ), suggesting that N1, N3, and NGR-2C bind within, or close to, the active site of the enzyme.

To exclude the possibility that the differential binding properties of N1, N3, and NGR-2C(Y) were related to differential Asn deamidation (with consequent NGRto-DGR/isoDGR transition and loss of affinity), we studied their deamidation kinetics. A mass spectrometry analysis of peptides before and after incubation in ammonium bicarbonate buffer, a condition known to promote rapid peptide deamidation, showed a 1-Da increase in the molecular mass of each NGR site after $22 \mathrm{~h}$ of incubation (Fig. S2(a) in the ESM). As the transition of $\mathrm{N}$ to $\mathrm{D} / \mathrm{isoD}$ causes the gain of $1 \mathrm{Da}$, these data suggest that all of the peptides were completely deamidated after incubation. Accordingly, a competitive binding assay to $\alpha v \beta 3$ showed that fifty percent of the NGR-to-isoDGR transition occurred after approximately $2 \mathrm{~h}$ of incubation for all peptides (Fig. S2(b) in the ESM), pointing to similar kinetics. Thus, the different affinities of these peptides to CD13 were not related to differential kinetics of Asn deamidation. More likely, they were related to the different scaffolds, which could affect the NGR structure or directly contribute to CD13 binding. The higher affinity of N1 (with G before NGR) compared to N3 and NGR-2C (both with $C$ before NGR) suggests that a $G / C$ change at this position markedly affects binding. In contrast, the similar affinity of N3 and NGR-2C (with G or C after NGR, respectively) suggests that the G/C change at this position is less important.

The capability of N1, N3, Iso1, and Iso3 to recognize integrins was also characterized by an $\alpha v \beta 3$-competitive binding assay. Micromolar concentrations of N1 competed with the binding of a CisoDGRC-peroxidase conjugate to $\alpha v \beta 3$ (EC F0: $\left._{10} \mu \mathrm{M}\right)$ (Fig. S3 in the ESM). The apparent binding was likely indirect and related to the formation of a small amount $(0.1 \%)$ of isoDGR during the assay, as Iso1 inhibited binding at 1,000fold lower concentrations ( $E_{50}$ : about $10 \mathrm{nM}$ ). Similar results were obtained with N3 and Iso3 (Fig. S3 in the ESM).

\subsection{Preparation and characterization of NGR- and IsoDGR-albumin conjugates}

The peptides N1 and N3 and the corresponding Iso1 and Iso3 deamidation products were selected for gold functionalization. Given the capability of gold 
(a)

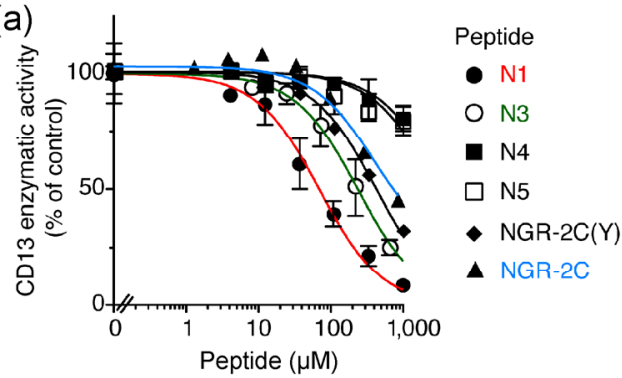

(b)

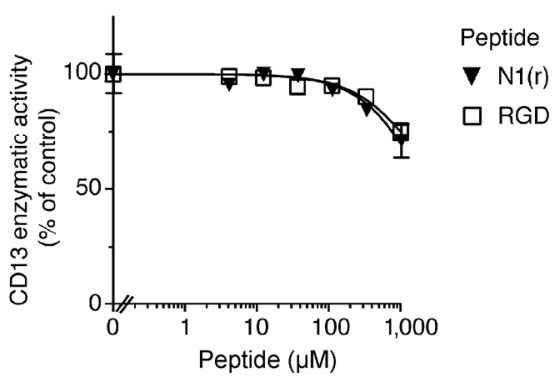

(c)
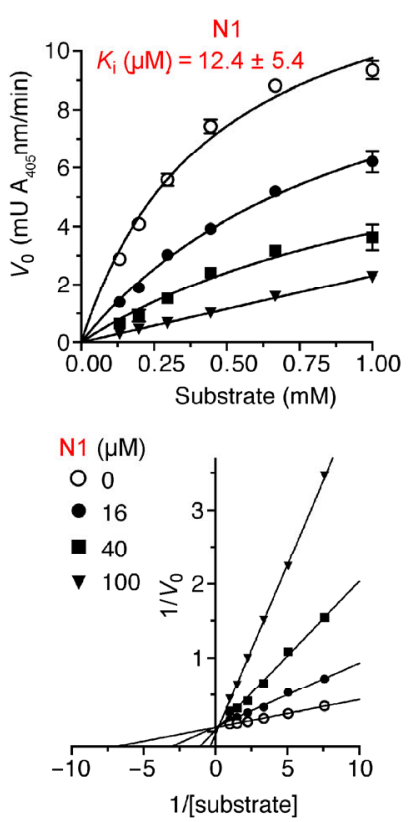
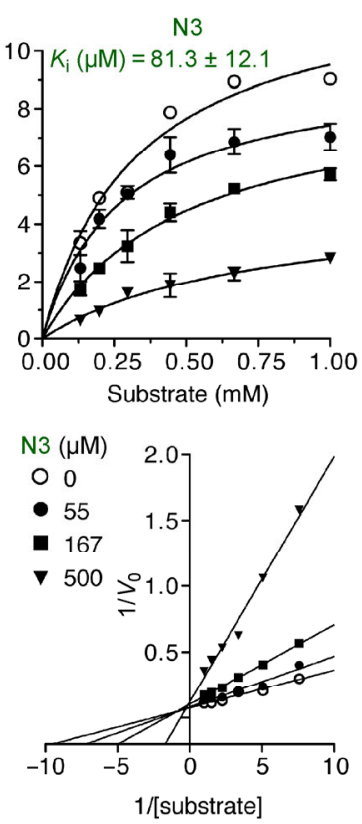
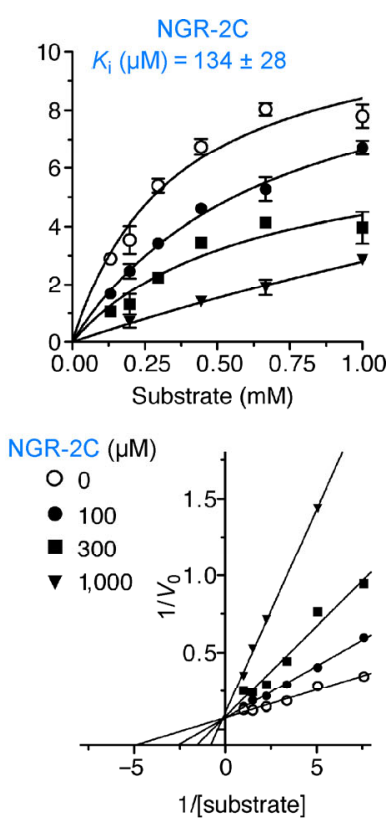

Figure 2 Effect of NGR peptides with different molecular scaffolds on CD13 enzymatic activity. Recombinant human histidine-tagged CD13 $(200 \mathrm{ng} / \mathrm{mL})$ was mixed with different amounts of peptides. The mixture were then added to a solution containing the L-alanine p-nitroanilide substrate and incubated for $30 \mathrm{~min}\left((\mathrm{a})\right.$ and (b)) at $37^{\circ} \mathrm{C}$, or $5 \mathrm{~min}$ at room temperature (c). The formation of p-nitroanilide product was quantified spectrophotometrically (A405 nm). (a) and (b) Representative experiments $(n=2-3)$ are shown (mean $\pm \mathrm{SE}$ ). See also Table S2 in the ESM. (c) Steady state kinetic analysis of CD13 in the presence of various amounts of L-alanine p-nitroanilide substrate and N1, N3, or NGR-2C peptide. Representative plots of initial velocity $\left(V_{0}\right)$ versus substrate concentration ((c), upper panels) and double reciprocal plot $\left((\mathrm{c})\right.$, lower panels) (mean $\pm \mathrm{SE}$, in quadruplicate). The inhibitory constant $\left(K_{\mathrm{i}}\right)$ reported in the plot is the result of two independent experiments (mean $\pm \mathrm{SE}$ ).

nanoparticles to strongly bind human serum albumin (HSA), we prepared peptide-HSA conjugates (called N1-, N3-, Iso1-, and Iso3-HSA) using sulfosuccinimidyl4-[N-maleimidomethyl]cyclohexane-1-carboxylate (sulfo-SMCC) as a bifunctional cross-linker, and used these conjugates for nanogold functionalization. In parallel, we prepared a sulfo-SMCC-activated HSA lacking the targeting peptide (called ${ }^{*} \mathrm{HSA}$ ) as a control. Analytical gel-filtration high-performance liquid chromatography and mass spectrometry showed that all peptide-albumin conjugates consisted of monomeric albumin modified with 5-6 linkers and 2-6 peptide molecules (Figs. S4(a) and S4(b) in the
ESM). Integrin binding assays showed no binding of N1- and N3-HSA to $\alpha v \beta 3$, even at concentrations of 3,000 $\mathrm{nM}$, whereas Iso1-HSA and Iso3-HSA could bind $\alpha v \beta 3$ with $K_{\mathrm{i}}$ values of approximately $5 \mathrm{nM}$ (Table 1 ). These data suggest that isoDGR contaminants in the NGR conjugates were $<0.1 \%$. However, N1- and N3-HSA, after forced deamidation in ammonium bicarbonate buffer $\left(16 \mathrm{~h}\right.$ at $\left.37^{\circ} \mathrm{C}\right)$, could bind $\alpha \mathrm{v} \beta 3$ with $K_{\mathrm{i}}$ values of approximately $5 \mathrm{nM}$ (Table 1), similar to the isoDGR counterparts. Furthermore, when we performed deamidation studies in cell culture medium (Dulbecco's modified Eagle medium, DMEM) at $37^{\circ} \mathrm{C}$, i.e., in physiological conditions, we observed that the 
Table 1 Binding of N1-, N3-, Iso1-, and Iso3-HSA to different integrins as measured by a competitive binding assay using a CisoDGRC-HRP conjugate

\begin{tabular}{|c|c|c|c|c|c|c|c|c|c|c|}
\hline \multirow{3}{*}{ Competitor } & \multicolumn{10}{|c|}{ Competitive binding $\left(K_{\mathrm{i}}{ }^{\text {a }}\right.$ values in $\left.n \mathrm{M}\right)$ to } \\
\hline & \multicolumn{2}{|c|}{$\alpha v \beta 3$} & \multicolumn{2}{|r|}{$\alpha v \beta 5$} & \multicolumn{2}{|r|}{$\alpha v \beta 6$} & \multicolumn{2}{|r|}{$\alpha v \beta 8$} & \multicolumn{2}{|r|}{$\alpha 5 \beta 1$} \\
\hline & $n^{\mathrm{b}}$ & $K_{\mathrm{i}}$ & $n$ & $K_{\mathrm{i}}$ & $n$ & $K_{\mathrm{i}}$ & $n$ & $K_{\mathrm{i}}$ & $n$ & $K_{\mathrm{i}}$ \\
\hline N1-HSA & 1 & $>3,000^{\mathrm{c}}$ & & nd $^{\mathrm{d}}$ & & nd & & nd & & nd \\
\hline N1-HAS $\left(37^{\circ} \mathrm{C}\right)^{\mathrm{e}}$ & 2 & $3.9 \pm 0.9$ & & nd & & nd & & nd & & nd \\
\hline N3-HSA & 1 & $>3,000$ & & nd & & nd & & nd & & nd \\
\hline $\mathrm{N} 3-\mathrm{HSA}\left(37^{\circ} \mathrm{C}\right)$ & 2 & $6.1 \pm 1.9$ & & nd & & nd & & nd & & nd \\
\hline Iso1-HSA & 6 & $\begin{array}{l}4.8 \pm 0.9 \\
(1) \mathrm{f}\end{array}$ & 3 & $\begin{array}{l}25.5 \pm 5.6 \\
(5.3)\end{array}$ & 4 & $\begin{array}{c}1,445 \pm 666 \\
(301)\end{array}$ & 2 & $\begin{array}{c}29,086 \pm 1875 \\
(6059)\end{array}$ & 3 & $\begin{array}{c}172 \pm 29 \\
(36)\end{array}$ \\
\hline Iso3-HSA & 3 & $\begin{array}{c}4.7 \pm 1.8 \\
\text { (1) }\end{array}$ & 2 & $\begin{array}{c}7.1 \pm 1.6 \\
(1.5)\end{array}$ & 3 & $\begin{array}{c}127 \pm 43 \\
(27)\end{array}$ & 4 & $\begin{array}{c}116 \pm 4 \\
(25)\end{array}$ & 3 & $\begin{array}{c}39 \pm 5.1 \\
(8.3)\end{array}$ \\
\hline *HSA & 1 & $>10,000$ & 1 & $>10,000$ & 1 & $>10,000$ & 1 & $>10,000$ & 1 & $>10,000$ \\
\hline
\end{tabular}

${ }^{\mathrm{a}} K_{\mathrm{i}}$, equilibrium dissociation constant of the competitor (mean $\pm \mathrm{SE}$ ). $K_{\mathrm{i}}$ was determined using a competitive binding assay as described previously [24]. ${ }^{\mathrm{b}} n$, number of independent experiments (each in duplicate). ${ }^{\mathrm{c}}>$, maximum concentration tested that had no inhibitory effect. ${ }^{\mathrm{d}}$ nd, not determined. ${ }^{\mathrm{e}} 37^{\circ} \mathrm{C}$, the conjugate was incubated overnight at $37^{\circ} \mathrm{C}$ in $0.1 \mathrm{M}$ ammonium bicarbonate buffer, pH 8.5 , to favor NGR-to-isoDGR conversion. ${ }^{\mathrm{f}}$ Relative values to $\alpha \mathrm{v} \beta 3 K_{\mathrm{i}}$.

half-lives of N1- and N3-HSA were 10 and $15 \mathrm{~h}$, respectively (Fig. S4(c) in the ESM). These data indicate that no significant deamidation occurred during conjugate preparation and that significant deamidation may occur during lengthy in vitro or in vivo assays. Thus, the potential transition of NGR to isoDGR during assay incubation was taken into account in all subsequent studies.

To assess the capability of NGR peptide-albumin conjugates to recognize CD13 on cell membranes, we analyzed the interactions of each conjugate (labeled with the fluorescent compound IRDye 680) with human umbilical vein endothelial cells (HUVECs) and human breast adenocarcinoma cells (MCF-7), i.e., with CD13positive and -negative cells. Based on a preliminary characterization of these cells by a FACS analysis with specific antibodies; HUVECs were $\mathrm{CD} 13^{+}, \alpha \mathrm{v} \beta 3^{+}$, $\alpha v \beta 5^{+}$, and $\alpha 5 \beta 1^{+}$, whereas MCF7 cells were CD13-, $\alpha v \beta 3^{-}, \alpha v \beta 5^{+}$, and $\alpha 5 \beta 1^{+}$(Fig. 3(a)).

Interestingly, cell binding assays with fluorescent conjugates showed that N1-HSA $(140 \mathrm{nM})$ could weakly bind HUVECs $\left(\mathrm{CD}^{+} 3^{+}\right.$, but not MCF-7 cells (CD13-) (Fig. 3(b)). In contrast, N3-HSA (140 nM) could bind both cell lines (Fig. 3(b)). The unexpected binding of $140 \mathrm{nM}$ N3-HSA to CD13- cells likely accounted for isoDGR formation during the assay, as suggested by the observation that Iso3-HSA (the deamidation product of N3-HSA) could significantly bind MCF-7 cells, even at sub-nanomolar levels (Fig. 3(c)). Indeed, considering the rapid deamidation kinetics of N3 in cell culture medium (see above), it is very likely that the nonspecific binding of $140 \mathrm{nM} \mathrm{N3-HSA}$ to CD13cells was related to the formation of $1 \%-2 \%$ Iso3-HSA during assay incubation; it is a high-affinity ligand of $\alpha v \beta 5$ and $\alpha 5 \beta 1$ (see Table 1 for integrin binding affinity), both of which are expressed by MCF-7 cells. In contrast, Iso1-HSA could bind MCF-7 cells only at concentrations of $>50 \mathrm{nM}$ (Fig. 3(c)), likely owing to its low affinity for $\alpha v \beta 5$ and $\alpha 5 \beta 1$ (Table 1) and the lack of $\alpha v \beta 3$ on these cells.

These data suggest that N1- and N3-HSA generate degradation products with different integrin receptor affinities and specificities, which may confound the interpretation of NGR interactions with membrane CD13. Thus, to clarify this point, we performed additional binding experiments using human acute lymphoblastic leukemia cells (MOLT-4), a cell line that does not express $\alpha \mathrm{v} \beta 3$-integrin (not shown), transfected with or without human CD13 cDNA (CD13/MOLT-4). Although a FACS analysis clearly showed the expression of CD13 by the transfected cells (Fig. S5(a) in the ESM), no binding was observed with $140 \mathrm{nM}$ 
(a)
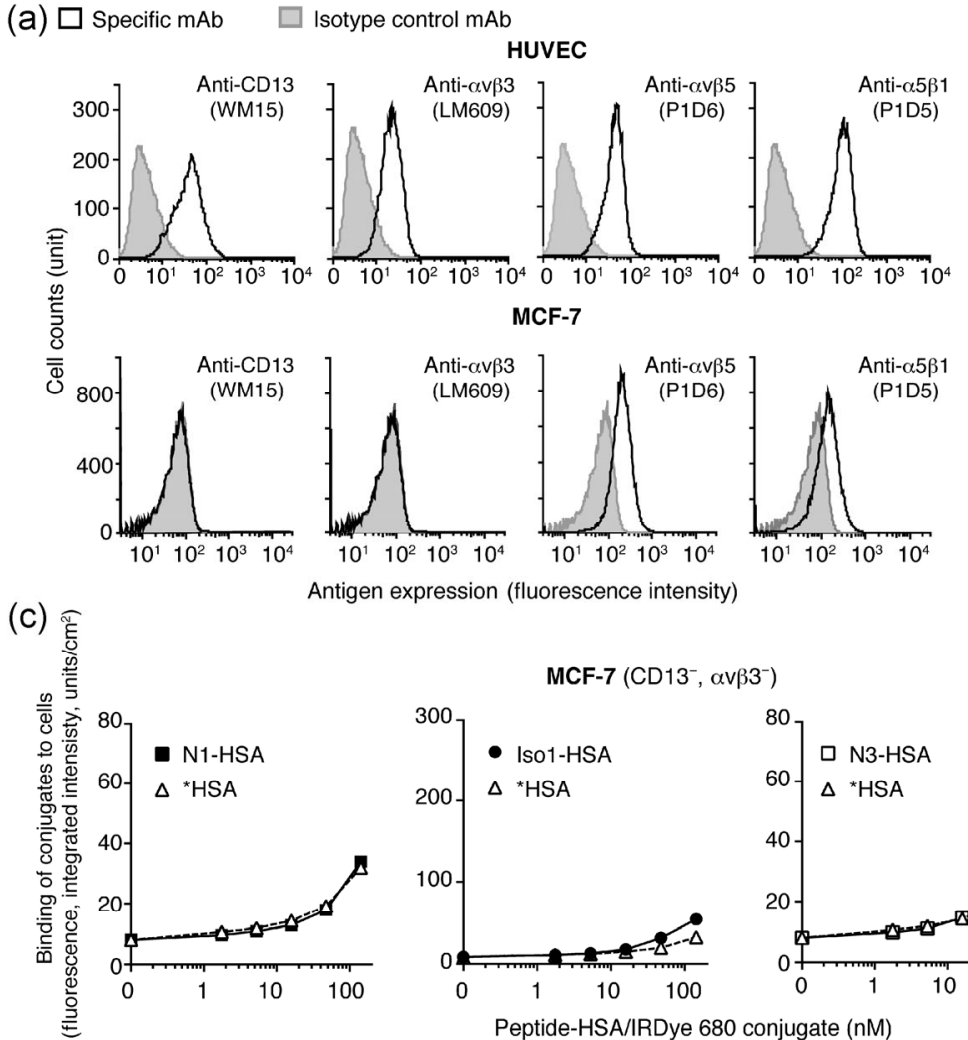

HUVEC

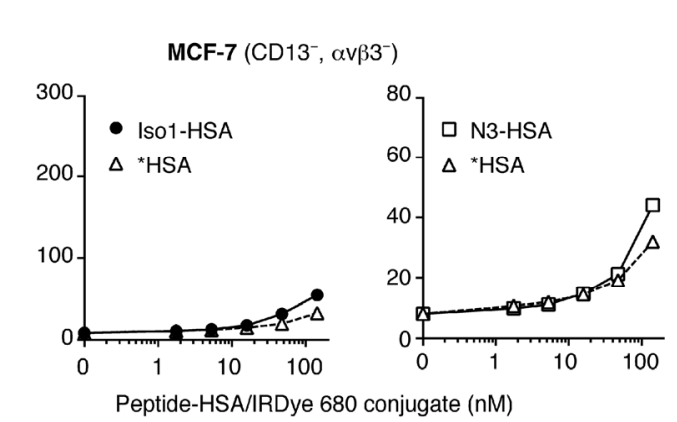

(b)
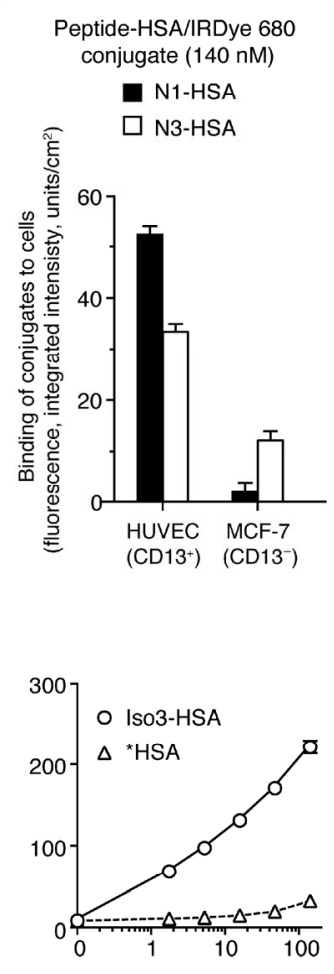

Figure 3 Binding of N1-, Iso1-, N3-, and Iso3-HSA to HUVECs and MCF-7. (a) Expression of CD13, $\alpha v \beta 3$, $\alpha v \beta 5$, and $\alpha 5 \beta 1$ by HUVECs and MCF-7 cells, as evaluated by a FACS analysis using the indicated mouse monoclonal antibody, followed by AlexaFluor 488-goat anti-mouse IgG polyclonal antibody. (b) and (c) Binding of the indicated peptide-HSA/IRDye 680 conjugate to HUVECs and MCF-7 cells. A dose of $140 \mathrm{nM}$ (b) or various amounts (c) of conjugates were added to cell monolayers (grown in 96-well microtiter plates) and incubated for $1 \mathrm{~h}$ at $37{ }^{\circ} \mathrm{C}, 5 \% \mathrm{CO}_{2}$ (see Experimental section). After washing, fluorescence was measured using an Odyssey CLx (LI-COR) scanner. In (b), the specific binding of N1- and N3-HSA was obtained by subtracting the binding of *HSA.

N1- or N3-HSA/IRDye 680 (Fig. S5(b) in the ESM). Higher concentrations could not be tested owing to the high levels of nonspecific binding of albumin to both cell lines. These data clearly show that low (nanomolar) concentrations of NGR cannot bind the CD13 expressed by these cells in vitro.

This finding is consistent with the results of previous studies showing that NGR can recognize with high affinity a CD13 form expressed by the endothelium of tumor vessels, and not (or less efficiently) CD13 expressed by other tissues, which is an important pre-requisite for efficient and selective tumor vascular targeting. To verify that low concentrations of N1 can indeed interact with endothelial cells in tumors, we injected $20 \mu \mathrm{g}$ of N1-HSA/IRDye 680 or *HSA/IRDye 680 to mice bearing WEHI-164 fibrosarcomas (a dose that generates $100-200 \mathrm{nM}$ peak levels) and analyzed their binding to tumors, spleens, and kidneys by a fluorescence analysis after organ explantation. Both conjugates accumulated in tumors and, to a lesser extent, in the spleen and kidney (Figs. 4(a) and 4(b)).

Significantly higher N1-HSA/IRDye 680 binding than HSA/IRDye 680 binding was observed in tumors, but not in the spleen or kidney, two CD13-rich organs. A FACS analysis of tumor cells after tissue disaggregation showed an increased accumulation on $\mathrm{CD} 31^{+} \mathrm{CD} 45^{-}$cells (endothelial cells), but not on $\mathrm{CD} 31^{-} \mathrm{CD} 45^{-}$(tumor cells) or $\mathrm{CD} 5^{+}$cells (leukocytes) (Fig. 4(c)). Notably, the relative staining of endothelial cells/leukocytes was significantly higher for N1-HSA/ IRDye 680 than controls, but not for *HSA/IRDye 680 compared to controls (Fig. 4(d)). These results suggest that low concentrations of N1-HSA can indeed interact with endothelial cells in tumors. 
(a)

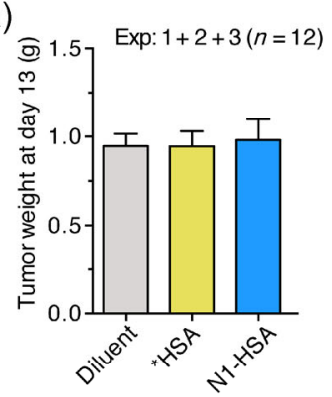

(c)

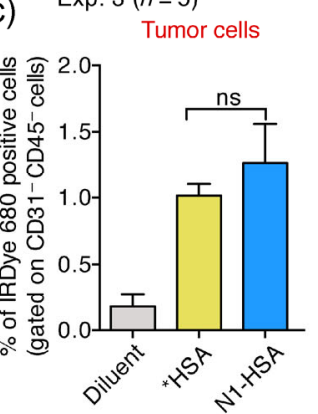

(b)

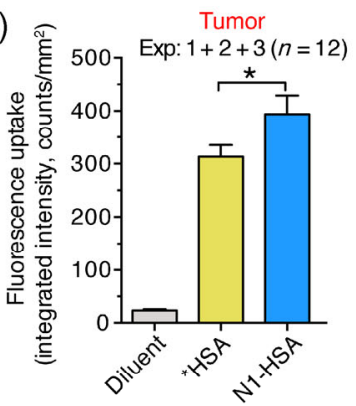

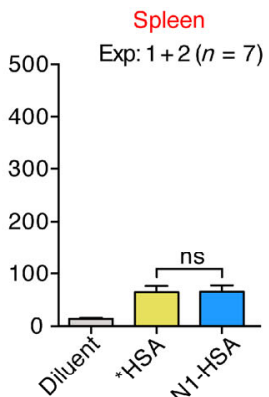

(d)
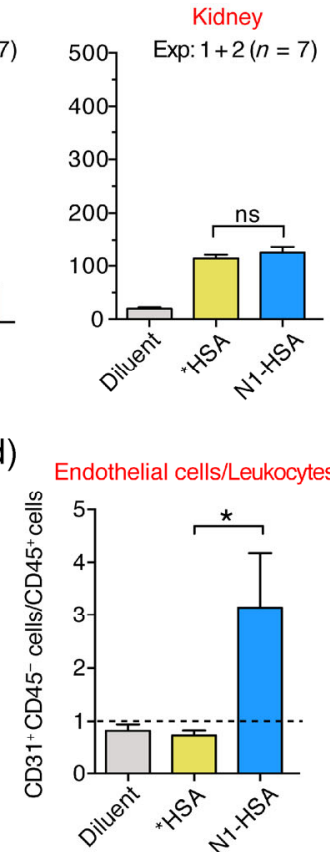

Figure 4 Tumor uptake of N1-HSA/IRDye 680 and *HSA/IRDye 680. (a) and (b) WEHI-164 tumor-bearing mice were injected i.v. with $20 \mu \mathrm{g}$ of N1-HSA/IRDye 680 or *HSA/IRDye 680 or with diluent. After $24 \mathrm{~h}$, tumors, spleen, and kidneys were explanted, weighted, and analyzed with an Odyssey scanner to quantify the fluorescence uptake. Cumulative result of 2-3 independent experiments as indicated ( $n$, number of mice). (c) Tumors were disaggregated and analyzed by FACS using anti-CD31 and anti-CD45 antibodies (see Experimental Section). (d) Ratio between $\mathrm{CD} 31^{+} \mathrm{CD} 45^{-}$and $\mathrm{CD} 45^{+}$cells (endothelial cells/leukocytes).

\subsection{Preparation and characterization of peptide- tagged gold nanoparticles loaded with TNF}

Bifunctional gold nanoparticles bearing peptide-HSA and recombinant murine TNF were then prepared for in vivo studies. Gold nanoparticles were tagged with peptide-HSA and TNF by incubating colloidal gold with mixtures of these compounds. In particular, four nanodrugs, called N1/, N3/, Iso1/, and Iso3/Au/TNF, were prepared by incubating colloidal gold with TNF solutions pre-mixed with N1-, N3-, Iso1-, or Iso3-HSA, respectively.

The size and the aggregation state of each nanodrug were characterized by UV-visible (UV-Vis) spectrophotometry, dynamic light scattering (DLS), transmission electron microscopy (TEM), and zeta-potential analyses. The UV-Vis absorption spectra for each product showed single peaks at 528-530 nm (Fig. 5(a) and a $650 \mathrm{~nm} / 530 \mathrm{~nm}$ ratio $<0.1$ (Table 2), which are consistent with products containing small amounts of or no aggregates. Furthermore, TEM showed that gold nanoparticles had an average diameter of approximately $25 \mathrm{~nm}$ (Fig. 5(b) and Table 2), and a zeta-potential analysis showed that all nanodrugs had a similar negative charge (Table 2). These results indicate that the four nanodrugs had very similar physico-chemical properties, and were mono-dispersed. Remarkably, two freezing/thawing cycles and lyophilization/resuspension did not cause nanoparticle aggregation as determined by UV-visible spectrophotometric analysis (not shown).

The presence of functional TNF on gold nanoparticles was checked by a cytotoxicity assay, as well as by anti-TNF antibodies and soluble TNF receptor 2 (sTNF-R2) binding assays. The presence of functional peptides was checked by $\alpha \mathrm{v} \beta 3$ binding assays (before and after forced deamidation for NGR-containing drugs). The cytotoxicity assay showed that 1-4 and 9-16 bioactive TNF molecules/nanoparticle were present in conjugates prepared at $\mathrm{pH} 6.0$ and $\mathrm{pH} 6.5$ (Table 2). Furthermore, all TNF-bearing nanodrugs could bind TNF receptors (sTNF-R2) spotted onto nitrocellulose filters, suggesting that the receptor-binding properties of TNF were preserved after adsorption on the gold surface (Fig. 5(c), left panel). Of note, after $48 \mathrm{~h}$ of incubation of the TNF-bearing nanodrug, $15 \%$ of TNF 
(a) - Nanodrugs --- Uncoated gold nanoparticles
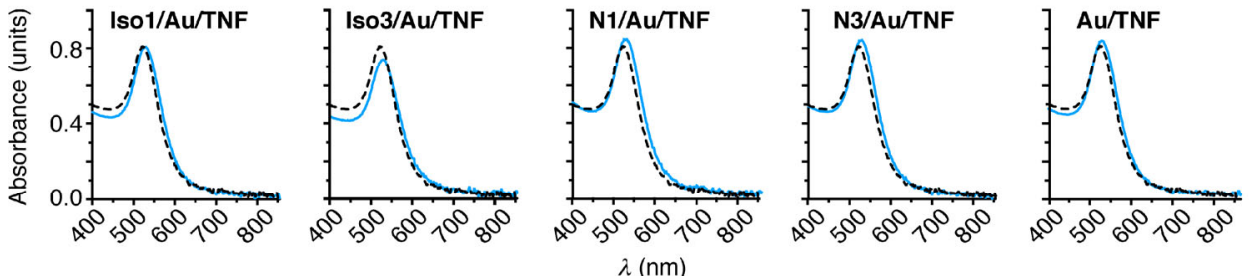

(b)
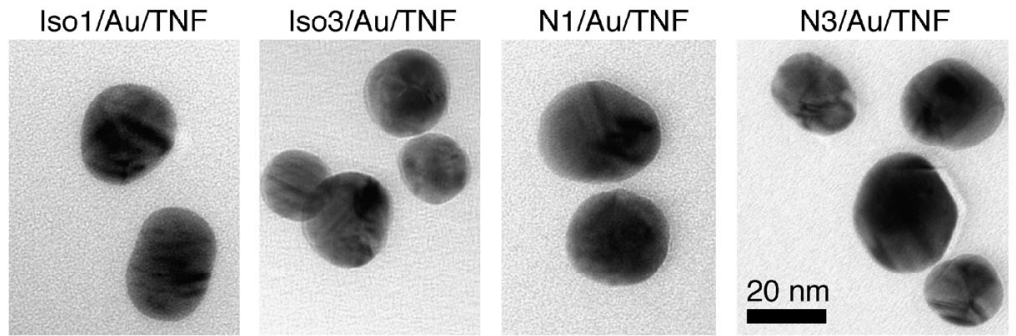

$\mathrm{Au} / \mathrm{TNF}$

(c)

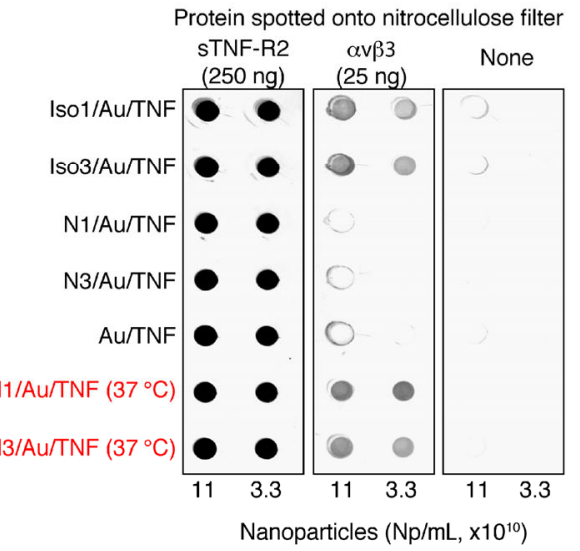

(d)

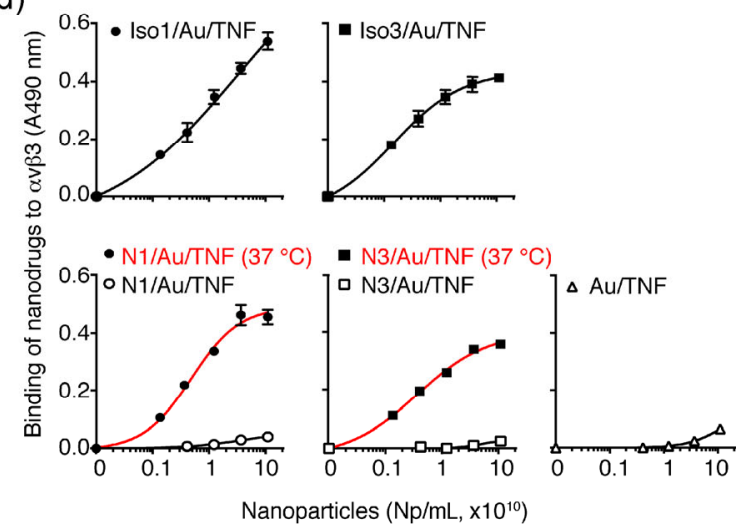

Figure 5 Characterization of TNF-based nanodrugs by UV-Vis spectrophotometry, TEM, and binding assays using $\alpha \mathrm{v} \beta 3$ and sTNF-R2. (a) UV-Vis absorption spectra of N1/, N3/, Iso1/, Iso3/Au/TNF, and Au/TNF. Dotted line corresponds to uncoated 25-nm gold nanoparticles. (b) A representative microphotograph of each nanodrug. (c) Binding of nanodrugs to sTNF-R2 and $\alpha v \beta 3$ spotted onto nitrocellulose filters, as detected by silver staining of gold nanoparticles. The binding of N1/ and N3/Au/TNF after heat-treatment $\left(37^{\circ} \mathrm{C}\right)$, i.e., after forced deamidation, is also shown (in red). (d) Binding of nanodrugs to $\alpha \mathrm{v} \beta 3$ adsorbed onto microtiter plates as detected with anti-TNF antibodies and HRP-labeled secondary antibodies.

was released in solution (half-life, 10-12 h) (Fig. S6(d) in the ESM). Binding studies to $\alpha \mathrm{v} \beta 3$ spotted onto nitrocellulose filters showed that Iso1/ and Iso3/Au/ TNF, but not N1/, N3/Au/TNF, and Au/TNF, could bind $\alpha \mathrm{v} \beta 3$, suggesting that no NGR deamidation occurred during nanodrug preparation (Fig. 5(c), middle panel). However, after forced deamidation, both $\mathrm{N} 1 /$ and N3/Au/TNF could efficiently bind $\alpha \mathrm{v} \beta 3$, suggesting that N1- and N3-HSA conjugates were successfully loaded on gold nanoparticles (Fig. 5(c), middle panel). Similar results were also obtained when $\alpha v \beta 3$ was adsorbed onto microtiter plates and the binding of each nanodrug was detected using anti-
TNF antibodies (Fig. 5(d)). Taken together, the above results suggest that the bifunctional properties of $\mathrm{N} 1 /$, N3/, Iso1/, and Iso3/Au/TNF were preserved, i.e., ligand targeting and TNF activity.

\subsection{Anti-tumor activity of TNF-based nanodrugs}

The in vivo antitumor properties of each nanodrug were then investigated using the WEHI-164 fibrosarcoma model. In the first set of experiments, tumor-bearing mice were treated (i.v.) with a dose of nanodrugs equivalent to $5 \mathrm{pg}$ of bioactive TNF, a dose that is completely inactive in this model when free TNF is used. Interestingly, N1/Au/TNF delayed 
Table 2 Characterization of TNF-based nanodrugs by UV-Vis spectroscopy, DLS, cytotoxicity assays, TEM, and zeta-potential analyses

\begin{tabular}{|c|c|c|c|c|c|c|c|}
\hline \multirow[b]{2}{*}{ Nanodrugs ${ }^{a}$} & \multicolumn{3}{|c|}{ UV-Vis ${ }^{b}$} & \multirow{2}{*}{$\begin{array}{c}\text { DLS }^{\mathrm{c}} \\
\operatorname{Radius}_{(\mathrm{nm})}\end{array}$} & \multirow{2}{*}{$\begin{array}{c}\text { TNF } \\
\text { molecule/Np }\end{array}$} & \multirow{2}{*}{$\begin{array}{c}\text { TEM }^{\mathrm{e}} \\
\text { Diameter }(\mathrm{nm})^{\text {Diame }}\end{array}$} & \multirow{2}{*}{$\begin{array}{c}\text { Zeta-potential }^{\mathrm{f}} \\
(\mathrm{mV})\end{array}$} \\
\hline & $\begin{array}{l}\lambda_{\max } \\
(\mathrm{nm})\end{array}$ & $\begin{array}{l}\text { PW 75\% } \\
\text { (nm) }\end{array}$ & $\begin{array}{c}650 \mathrm{~nm} \\
1530 \mathrm{~nm}\end{array}$ & & & & \\
\hline \multicolumn{8}{|c|}{$(160 \mu \mathrm{g}: 16 \mu \mathrm{g}) ; \mathrm{pH} 6.0$} \\
\hline $\mathrm{N} 1 / \mathrm{Au} / \mathrm{TNF}$ & $531 \pm 3$ & $59 \pm 1.7$ & $0.08 \pm 0.02$ & 16.1 & $-15.9 \pm 7.1$ & $1.2 \pm 0.2$ & $25.8 \pm 1.2$ \\
\hline $\mathrm{N} 3 / \mathrm{Au} / \mathrm{TNF}$ & $531 \pm 3$ & $59 \pm 0.4$ & $0.09 \pm 0.01$ & 17.7 & $-14.5 \pm 6$ & $1.1 \pm 0.2$ & $26.2 \pm 1.0$ \\
\hline Iso $1 / \mathrm{Au} / \mathrm{TNF}$ & $528 \pm 1$ & $59 \pm 0.7$ & $0.09 \pm 0.01$ & $21.6 \pm 3.9$ & $-15.2 \pm 6.7$ & $3.4 \pm 0.7$ & $25.4 \pm 1.1$ \\
\hline Iso3/Au/TNF & $530 \pm 2$ & $59 \pm 0.4$ & $0.06 \pm 0.01$ & 16.8 & nd & $2.8 \pm 0.4$ & $\mathrm{nd}^{\mathrm{g}}$ \\
\hline $\mathrm{Au} / \mathrm{TNF}$ & $528 \pm 2$ & $58 \pm 0.1$ & $0.09 \pm 0.01$ & 22.1 & $-13.1 \pm 5.2$ & $3.6 \pm 0.7$ & $27.5 \pm 1.1$ \\
\hline \multicolumn{8}{|c|}{$(160 \mu \mathrm{g}: 32 \mu \mathrm{g}) ; \mathrm{pH} 6.5$} \\
\hline $\mathrm{N} 1 / \mathrm{Au} / \mathrm{TNF}$ & $529 \pm 2$ & 57.7 & 0.09 & 16.4 & $-16.7 \pm 5.5$ & $9.0 \pm 2.9$ & $24.9 \pm 1.0$ \\
\hline Iso $1 / \mathrm{Au} / \mathrm{TNF}$ & $526 \pm 1$ & $58 \pm 0.7$ & $0.09 \pm 0.03$ & 23.1 & $-15.6 \pm 6.2$ & $16.3 \pm 1.4$ & $27.2 \pm 1.0$ \\
\hline Uncoated gold & $523 \pm 2$ & $57 \pm 1.2$ & $0.07 \pm 0.02$ & $15.5 \pm 1.6$ & nd & 0 & nd \\
\hline
\end{tabular}

${ }^{a}$ Nanodrugs were prepared by mixing peptide-HSA and TNF at the indicated ratios with $1 \mathrm{~mL}$ of gold (pH 6.0 or 6.5 , as indicated). ${ }^{\mathrm{b}} \lambda_{\max }$, wavelength of peak absorbance; PW 75\%, peak-width at $75 \%$ of height; mean $\pm \mathrm{SD} .{ }^{\mathrm{c}}$ Mean \pm SD of 2 independent analyses.

${ }^{\mathrm{d}}$ Number of bioactive TNF molecules/nanoparticle, as determined by a cytotoxicity assay [25], mean $\pm \mathrm{SE}$ (5-8 independent experiments).

${ }^{\mathrm{e}}$ Particle diameter was obtained by measuring the width of about 30 particles using ImageJ software. Mean $\pm \mathrm{SE} .{ }^{\mathrm{f}} \mathrm{Mean} \pm \mathrm{SD} .{ }^{\mathrm{g}} \mathrm{nd}$, not determined.

tumor growth more efficiently than N3/Au/TNF and $\mathrm{Au} / \mathrm{TNF}$ (Fig. 6(a)). The stronger activity of N1/ versus $\mathrm{N} 3 / \mathrm{Au} / \mathrm{TNF}$ is consistent with the CD13 binding properties of the peptides observed in vitro, and N1 was 3-4-fold more efficient than N3 with respect to CD13 recognition (Table S2 in the ESM). Furthermore, the stronger activity of $\mathrm{N} 1 / \mathrm{Au} / \mathrm{TNF}$ compared to $\mathrm{Au} / \mathrm{TNF}$ suggests that the peptide-mediated "active" targeting mechanism is important for its anti-tumor activity. We also observed that 5 pg of Iso1/Au/TNF, i.e., the main degradation product of $\mathrm{N} 1 / \mathrm{Au} / \mathrm{TNF}$, delayed tumor growth to a similar extent or even stronger than N1/Au/TNF (Fig. 6(a)), suggesting that this degradation product is biologically active. Notably, Iso3/Au/TNF was less active then Iso1/Au/TNF.

Based on dose-escalation studies using nanodrugs loaded with 1-4 or with 9-16 TNF molecules/ nanoparticle, the dose-response curves for each drug tended to be U-shaped (Fig. 6(b)). Similarly, NGR-TNF (CNGRCG-TNF fusion protein) showed a U-shaped dose-response curve (Fig. 6(b)). We have previously demonstrated that the U-shaped dose-response curve of NGR-TNF is related to the activation of counterregulatory mechanisms by high doses, such as soluble receptor shedding, which inhibits TNF activity [1]. The same likely applies to TNF-based nanodrugs. Interestingly, nanodrugs with a fewer TNF molecules/ nanoparticle were more efficient (Fig. 6(b)), likely because a higher number of injected nanoparticles was necessary to achieve the same TNF dose and, consequently, to increase the active/passive targeting effect. No evidence of toxicity, as judged by animal weight loss, was observed for any tested dose and drug. Remarkably, 1 pg of Iso1/Au/TNF induced antitumor effects similar to that of 10-20 pg of N1/Au/TNF (Fig. 6(b)), suggesting that Iso1 is more efficient than N1 with respect to ligand targeting. This observation raises the question as to whether N1/Au/TNF activity was actually mediated by the in vivo formation of Iso1/Au/TNF and integrin targeting, rather than N1/ CD13 interactions. To rule out this possibility, we performed CD13 neutralization experiments with a) the antibody R363, an anti-murine CD13 antibody previously used to neutralize the anti-tumor activity of NGR-TNF and NGR-IFNgamma [2, 3], and b) with an excess of free $\mathrm{N} 1$ peptide. The anti-tumor activity of N1/Au/TNF was inhibited by co-administration with either the R363 or N1 peptide (Figs. 6(c) and 6(d)), 
(a)

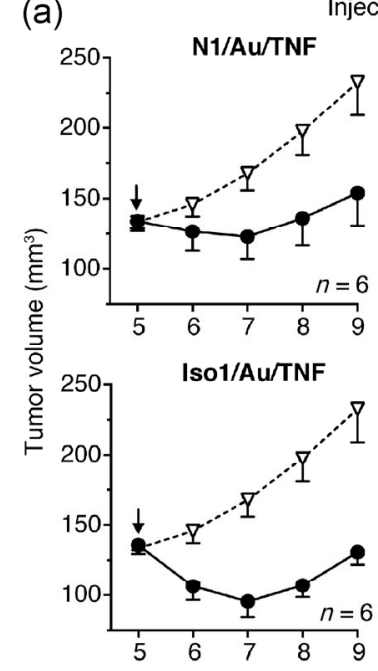

Inject

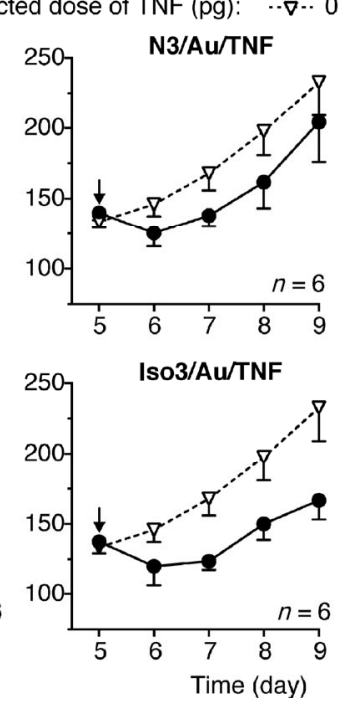

(b)
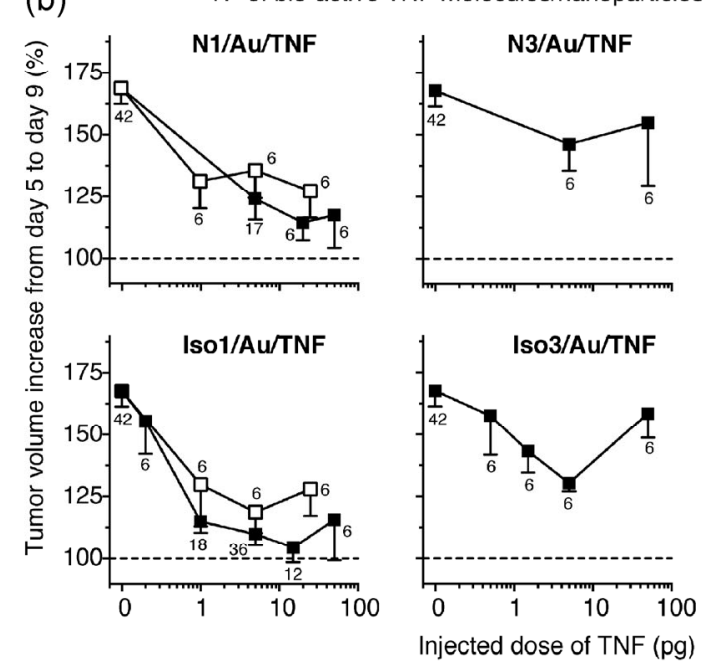

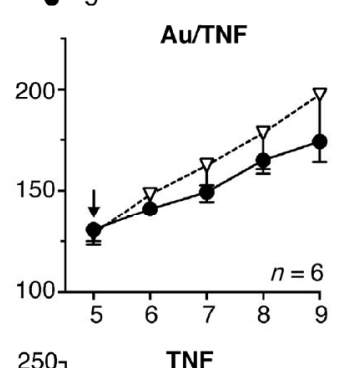

(c)

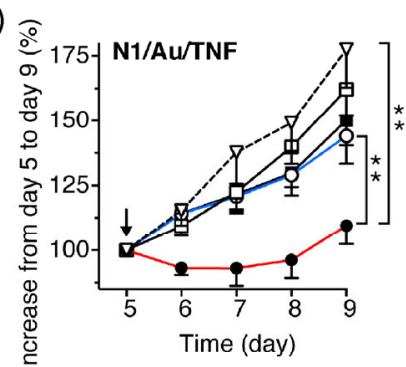

$-\nabla$ - Vehicle

$\square$ Control lgG2a $(15 \mu \mathrm{g})$

- N1/Au/TNF (20 pg) + control lgG2a $(15 \mu \mathrm{g})$

- N1/Au/TNF (20 pg)

$+\mathrm{R} 363(15 \mu \mathrm{g})$

- R363 $(15 \mu \mathrm{g})$

(d)

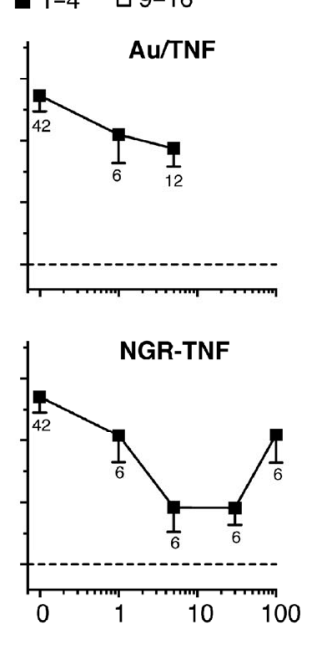

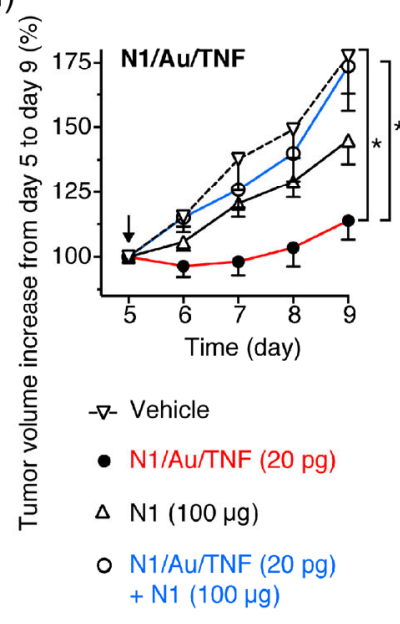

Figure 6 Anti-tumor effects of various formulations of TNF (N1/, N3/, Iso1/, Iso3/Au/TNF nanodrugs, TNF, and NGR-TNF) alone ((a) and (b)) or in combination with the neutralizing anti-CD13 antibody R363 (c) or peptide N1 (d) in the WEHI-164 fibrosarcoma model. (a) Anti-tumor effects of intravenous administration of the indicated drugs, at a dose corresponding to 5 pg of bioactive TNF. Arrows, time of treatment; tumor volumes (mean \pm SE, 6 mice/group). (b) Effect of various doses of the indicated nanodrugs (bearing 1-4 or 9-16 bioactive TNF molecules/nanoparticle) on the growth of tumors from day 5 to day 9. Dotted line: normalized tumor volumes at day 5. Numbers within the panels indicate the number of mice per dose (cumulative results of 1-7 independent experiments, with 6 mice/experiment, mean $\pm \mathrm{SE}$ ). (c) and (d) WEHI-tumor-bearing mice were treated at day 5 with N1/Au/TNF alone, in combination with mAb R363 (anti-murine CD13), with isotype matched control antibody (IgG2a), or with N1 at the doses indicated in each panel. Antibodies were given $2.5 \mathrm{~h}$ before N1/Au/TNF, whereas N1 was co-administered with N1/Au/TNF. Arrows indicate the day of treatment. Tumor volumes (mean $\pm \mathrm{SE}$ ). The area under the curve for each mouse was calculated using GraphPad Prism. Differences between calculated areas were evaluated by Mann-Whitney tests (6-8 animals per group; $\left.{ }^{* *}, P<0.01 ;{ }^{*}, P<0.05\right)$.

suggesting that the main mechanism underlying the activity of this nanodrug is indeed related to CD13 targeting, as originally hypothesized. Finally, to assess whether tumor cell targeting was necessary to induce anti-tumor effects, we performed an in vivo experiment using the RMA lymphoma model, taking advantage of the lack of $\mathrm{CD} 13$ and $\alpha \mathrm{v}$-integrin expression in RMA cells $[2,19]$. We observed that 5 pg of N1/Au/ $\mathrm{TNF}$, but not $\mathrm{Au} / \mathrm{TNF}$, could induce anti-tumor effects, suggesting that endothelial cell targeting is likely sufficient to induce anti-tumor effects (Fig. S7 in the ESM). 


\section{Discussion}

To tag TNF-bearing gold nanoparticles with a CD13 ligand, we selected the head-to-tail cyclized exa-peptide c(CGNGRG), called N1, which contains a free thiol group suitable for nanodrug coupling. The results of enzyme binding and inhibition experiments performed with recombinant soluble CD13 suggest that this peptide binds within, or close to, the active site $\left(K_{\mathrm{i}}=\right.$ $12.4 \mu \mathrm{M})$ 6-10-fold more efficiently than CNGRC (NGR-2C), a reference disulfide-bridged peptide, and c(CNGRGG) (N3), a similar head-to-tail cyclized exapeptide. Additionally, in vivo studies performed in tumor-bearing mice showed that gold nanoparticles coated with N1-HSA, a peptide-albumin conjugate, can deliver TNF to tumors more efficiently than nanoparticles coated with N3-HSA or with HSA alone. Interestingly, the observation that N1-tagged nanoparticles can deliver extremely low, yet pharmacologically active doses of TNF to tumors (e.g., $5 \mathrm{pg}$ ) implies that high-affinity interactions occurred between the N1/Au/TNF nanodrug and tumors. Furthermore, the finding that this effect was inhibited by the co-administration of an excess of $\mathrm{N} 1$ points to an important role of the N1 ligand in nanodrug delivery to tumors. This view is also supported by the observation that N1-HSA/IRDye 680, but not HSA/ IRDye 680, could bind to the expected targets, i.e., $\mathrm{CD} 31^{+} \mathrm{CD} 45^{-}$cells in tumors (endothelial cells).

The high-affinity interactions of these conjugates with tumor tissues cannot be explained by the NGR/ CD13 interactions observed in the in vitro experiments, which showed binding at micromolar concentrations and very weak (or undetectable) interactions at nanomolar levels. One explanation is that NGR binding affinity differs between the CD13 expressed in vivo by tumor vessels and the soluble recombinant CD13 or the CD13 form expressed by cells in our in vitro studies. This hypothesis is supported by the results of previous studies showing that phage viral particles displaying the NGR peptide can bind CD13-positive endothelial cells isolated from tumors, but not CD13positive myeloid-derived cells [26]. Other previous studies on the NGR bio-distribution have also shown that this peptide sequence can efficiently bind CD13 in tumors, but not (or less efficiently) other CD13positive tissues [15]. The structural determinants of the differential binding are unknown. An interesting possibility is that conformational changes in different tissues, possibly owing to tissue-specific cofactors or signaling molecules, results in differential NGR binding affinity. Indeed, natural CD13 is a type II membrane dimeric glycoprotein with an $\mathrm{N}$-terminal membrane anchor, resulting in an arch-like structure on the cell surface that may undergo large conformational changes because each monomer can assume open or closed conformations [27].

Other receptors expressed by endothelial cells might also contribute to the high-avidity interactions of N1/ $\mathrm{Au} / \mathrm{TNF}$ with tumor endothelial cells; for example, considering that this nanodrug contains albumin and TNF, albumin receptors (such as albondin, gp30, and gp18) [28] and membrane TNF receptors (TNF-R1 and TNF-R2) could be involved. In any case, the observation that $\mathrm{N} 1 / \mathrm{Au} / \mathrm{TNF}$ is more potent than Au/TNF in tumor animal models, and that the anti-CD13 antibody R363 or an excess of free N1 peptide completely reduces its activity to the level of $\mathrm{Au} / \mathrm{TNF}$ points to a major contribution of NGR/CD13 interactions in tumor drug delivery.

Although N1 characterization studies showed no binding to integrins at submicromolar concentrations, the notion that N1 can deamidate to generate Iso1, a high-affinity integrin ligand, and the observation that Iso1/Au/TNF acts as a potent nanodrug active at picogram doses in our animal models raises the question as to whether integrin binding contributes to N1-mediated targeted delivery. The marked inhibition of N1/Au/TNF by the anti-CD13 antibody R363 and by N1 suggests that the main mechanism underlying the activity of this nanodrug is related to CD13 targeting, as originally hypothesized, and not (or minimally) to integrin targeting. In previous studies, we have shown that the anti-tumor activity of a CNGRC-TNF fusion protein can be inhibited by an excess of CNGRC, but not of CisoDGRC (integrin ligand), whereas the activity of CisoDGRC-TNF can be inhibited by an excess of CisoDGRC, but not of CNGRC [19]. These results suggest that the binding of NGR to CD13 alone is sufficient for targeting and 
that the transition to isoDGR and consequent integrin recognition is not necessary for the observed activity.

Another important point is related to the impact of the number of TNF molecules/nanoparticles on nanodrug activity. Indeed, injecting the same dose of TNF formulated as a nanodrug bearing 1-4 or 9-16 TNF molecules/nanoparticle implies that a different number of nanoparticles are injected (e.g., 2-3 $210^{6}$ or $2-3 \times 10^{7}$ nanoparticles, respectively, for a dose of $5 \mathrm{ng}$ of TNF). This may have important consequences on activity, despite equal TNF doses, for the following reasons: (1) A higher number of injected nanoparticles could reach a higher number of endothelial cells in tumors and (2) a lower number of TNF molecules/ nanoparticles allows the loading of a higher number of peptide-albumin molecules on each nanoparticle, thereby increasing the overall targeting efficiency. Consistent with this view, we observed stronger effects with the nanodrug bearing 1-4 TNF molecules/ nanoparticle.

In conclusion, the results show that the N1 peptide has an improved affinity for CD13, is suitable for tagging colloidal gold, and (after coupling to nanogold) is an efficient carrier for TNF delivery to tumors. The favorable CD13-binding properties of N1 may overcome some of the problems related to the use of CNGRC as a gold-tagging peptide. Indeed, in the case of CNGRC, disulfide-gold interactions and disulfide exchange between adjacent peptides may occur in multivalent nanoparticles, thereby altering or hindering the NGR structure $[29,30]$. N1 overcomes this problem because cyclization is obtained via head-to-tail peptide bonds and not via cystine. Finally, the development of N1/ $\mathrm{Au} / \mathrm{TNF}$ overcomes a major obstacle in the use of TNF in patients, i.e., its low therapeutic index. Indeed, the clinical use of TNF is currently limited to loco-regional treatments in patients with sarcomas localized at the extremities owing to the prohibitive systemic toxicity. As no toxic reactions were observed in mice treated intravenously with extremely low doses of N1/Au/ TNF, this drug formulation could enable, in principle, systemic treatments of cancer patients with solid tumors. N1-tagged nanogold could potentially be loaded with other synergistic cytokines (e.g., IFN-gamma or EMAP-2), thereby enabling multicytokine delivery to endothelial cells in tumors.

\section{Experimental}

\subsection{Cell lines and reagents}

MCF-7 and murine WEHI-164 fibrosarcoma cells were cultured in DMEM supplemented with $10 \%$ fetal bovine serum, $2 \mathrm{mM}$ glutamine, $50 \mu \mathrm{g} / \mathrm{mL}$ streptomycin, $100 \mathrm{U} / \mathrm{mL}$ penicillin, and $0.25 \mu \mathrm{g} / \mathrm{mL}$ amphotericin-B. HUVECs were cultured in endothelial cell growth medium (EGM)-2 (Lonza, Walkersville, MD, USA). MOLT-4 cells (acute lymphoblastic leukemia) transfected with human CD13 cDNA (CD13/MOLT-4) were prepared and cultured as described previously [15].

Sulfo-SMCC was obtained from Pierce (Rockford, IL, USA), HSA was obtained from Baxter (Deerfield, IL, USA), and bovine serum albumin (BSA) was obtained from Sigma (St. Louis, MO, USA).

Murine tumor necrosis factor-alpha (TNF $\alpha$ ) was prepared as described previously [25]. TNF was dialyzed against $5 \mathrm{mM}$ citrate buffer, $\mathrm{pH} 6.0$ and stored in aliquots at $-20^{\circ} \mathrm{C}$.

NGR-TNF (consisting of TNF fused with the Cterminus of CNGRCG) was prepared by recombinant DNA technology and purified from Escherichia coli cell extracts as described previously [2].

Human $\alpha v \beta 3, \alpha v \beta 5$, and $\alpha 5 \beta 1$ integrins were obtained from Immunological Sciences (Rome, Italy); recombinant human $\alpha v \beta 6$ and $\alpha v \beta 8$ integrins were obtained from R\&D Systems (Minneapolis, MN, USA). Monoclonal antibodies WM15 and R363 (anti-human and -mouse CD13, respectively) were obtained from Acris Antibodies (San Diego, CA, USA), LM609, P1D6, and P1D5 (anti-human $\alpha \mathrm{v} \beta 3, \alpha v \beta 5$, and $\alpha 5 \beta 1$, respectively) were obtained from Immunological Sciences (Rome, Italy), and rat IgG2a isotype control antibody was obtained from BioLegend (San Diego, CA, USA).

\subsection{Peptide synthesis and characterization}

Head-to-tail cyclic peptides (see Fig. 1 for schematic representations of each peptide and peptide code) were prepared by the solid-phase Fmoc method [31]. Disulfide-bridged NGR peptide was prepared as described previously [18]. All peptides were dissolved in water and stored in aliquots at $-20^{\circ} \mathrm{C}$. The molecular mass of each peptide was checked by MALDI-TOF 
mass spectrometry (see Table S1 in the ESM). Thiolcontaining peptides were quantified using the Ellman's assay.

\subsection{CD13 enzymatic activity assay and CD13 com- petitive binding assay}

For the CD13 enzymatic activity assay, 96-well PVC microtiter plates were filled with a mixture of recombinant human His-tagged CD13 $(0.2 \mu \mathrm{g} / \mathrm{mL}$, Sino Biological Inc., Beijing, China), L-alanine-p-nitroanilide (0.5 mM; Sigma) and various amounts of peptide in $60 \mathrm{mM}$ potassium phosphate buffer, $\mathrm{pH} 7.4(100 \mu \mathrm{L} /$ well, final volume). The mixtures were then incubated for $30 \mathrm{~min}$ at $37^{\circ} \mathrm{C}$. The absorbance at $405 \mathrm{~nm}$ of the p-nitroanilide product was measured using an enzymelinked immunosorbent assay microtiter plate reader. The $\mathrm{IC}_{50}$ was calculated by a non-linear regression analysis of competitive inhibition data using GraphPad Prism (GraphPad Software, Version 6.00; San Diego, CA, USA).

Steady-state enzyme kinetic analyses were performed at room temperature $\left(23^{\circ} \mathrm{C}\right)$ in 96 -well plates as described above, using increasing concentrations of L-alanine-p-nitroanilide $(100-1,000 \mu \mathrm{M})$, at fixed concentrations of $\mathrm{N} 1$ ranging from 0 to $100 \mu \mathrm{M}$. The initial velocities $\left(V_{0}\right)$ were calculated from the slopes of the first $5 \mathrm{~min}$ of the reaction. The enzyme inhibitory constants $\left(K_{\mathrm{i}}\right)$ were calculated using the Competitive enzyme inhibition model of GraphPad Prism (GraphPad Software, Version 6.00).

A CD13 competitive binding assay with peptides was performed using microtiter plates coated with the anti-CD13 monoclonal antibody WM15 and His-tagged recombinant $\mathrm{CD} 13$ as described in the ESM.

\subsection{Preparation of peptide-HSA conjugates and characterization of their CD13 and integrin binding properties}

Peptide N1, N3-, Iso1-, and Iso3- were coupled to HSA as follows: HSA, $40 \mathrm{mg}$ in $380 \mu \mathrm{L}$ of $10 \mathrm{mM}$ phosphate buffer, $138 \mathrm{mM}$ sodium chloride, $2.7 \mathrm{mM}$ potassium chloride, $\mathrm{pH} 7.4$, containing $5 \mathrm{mM}$ EDTA (PBS-E) was mixed with sulfo-SMCC (2.4 mg in $120 \mu \mathrm{L}$ in water) and left to react for $1 \mathrm{~h}$ at room temperature.
Then, the mixture was purified by gel-filtration chromatography on a NAP-5 column (GE Healthcare Life Sciences, Little Chalfont, UK), pre-equilibrated with PBS-E. Aliquots of activated-HSA (20 mg) were mixed with various peptides $(1.5 \mathrm{mg}$, 9:1 peptide/HSA molar ratio) and reacted for $3 \mathrm{~h}$. Then, 2-mercaptoethanol was added ( $1 \mathrm{mM}$, final concentration) and incubated for $0.5 \mathrm{~h}$. The conjugates were gel-filtered through a PD10 column (GE Healthcare Life Sciences) preequilibrated with $10 \mathrm{mM}$ phosphate buffer, $138 \mathrm{mM}$ sodium chloride, $2.7 \mathrm{mM}$ potassium chloride, $\mathrm{pH} 7.4$, and stored at $-20{ }^{\circ} \mathrm{C}$. The protein concentration in each conjugate was determined spectrophotometrically (A280 nm).

The binding of peptide-HSA to cells was performed as follows: First peptide-HSA conjugates were labeled with the IRDye 680 RD-NHS-ester dye (LI-COR, Lincoln, NE, USA) by incubating mixtures of $590 \mu \mathrm{L}$ of each conjugate $(1.350 \mathrm{mg}$ in of $25 \mathrm{mM}$ Hepes, containing $150 \mathrm{mM} \mathrm{NaCl}$, pH 7.4 (Hepes buffer) with $90 \mu \mathrm{L}$ of dye $(2 \mathrm{mg} / \mathrm{mL}$ in dimethyl sulfoxide, 9:1 dye to HSA molar ratio) for $4 \mathrm{~h}$ at $4{ }^{\circ} \mathrm{C}$, and blocking with $1 \mathrm{M}$ glycine ( $50 \mathrm{mM}$, final concentration, for $0.5 \mathrm{~h}$ ). The conjugates were then dialyzed extensively against Hepes buffer ( $10 \mathrm{kDa}$, cut-off) and stored at $-80^{\circ} \mathrm{C}$.

The binding of peptide-HSA/IRDye 680 conjugates to HT-1080, HUVECs, and MCF-7 cells was then analyzed as follows. The cells were grown in 96-well clear-bottom black plates $\left(2-3 \times 10^{4}\right.$ cells/well, plated $48 \mathrm{~h}$ before the experiment). After washing with DMEM containing $1 \%$ fetal bovine serum and $3 \mathrm{mg} / \mathrm{mL} \mathrm{HSA}$ (binding buffer), each conjugate (0.2-150 $\mathrm{nM}$ in binding buffer) was added to the cells, followed by incubation for $1 \mathrm{~h}$ at $37^{\circ} \mathrm{C}, 5 \% \mathrm{CO}_{2}$. After three washings with binding buffer ( $3 \mathrm{~min}$ each), the cells were fixed with PBS containing $2 \%$ paraformaldehyde and $3 \%$ sucrose for $15 \mathrm{~min}$ at room temperature. Binding of conjugates to cells was quantified by scanning the plate with an Odyssey CLx (LI-COR). Then, the cells were counterstained with 4',6-diamidino-2-phenylindole (DAPI, a nuclear stain) and the plates were analyzed using a VICTOR3 (Perkin Elmer, Waltham, MA, USA) fluorescence plate reader to quantify the cell number in each well. 


\subsection{Quantification of N1-HSA/IRDye 680 conjugate uptake in tumors and tumor cell suspensions}

WEHI-164 tumor-bearing mice were treated i.v. with $20 \mu \mathrm{g}$ of N1-HSA/IRDye 680 or ${ }^{*} \mathrm{HSA} / \mathrm{IRDye} 680$ or with diluent. After $24 \mathrm{~h}$, the tumor, spleen and kidney were collected and analyzed with an Odyssey CLx scanner to assess the uptake of fluorescence (settings: $2 \mathrm{~mm} ; 1.5$ intensity; 700-nm filter). Then, tumors were minced, resuspended with a collagenase-D solution in RPMI medium ( $1 \mathrm{mg} / \mathrm{mL}, 3 \mathrm{~mL} / \mathrm{g}$ tumor tissue, Roche, Basel, Switzerland) and incubated for $1 \mathrm{~h}$ at $37^{\circ} \mathrm{C}$ under gentle agitation. Cell suspensions were filtered through a $70-\mu \mathrm{m}$ nylon cell-strainer and centrifuged. The pellets were resuspended in PBS containing 2\% FCS, Fc-blocking solution $(5 \mu \mathrm{g} / \mathrm{mL}$, BD Biosciences, Franklin Lakes, NJ, USA) and incubated for $10 \mathrm{~min}$ at room temperature. After washing, the cells were incubated with the fluorescence labeled-monoclonal antibodies anti-CD45-V500 $(2 \mu \mathrm{g} / \mathrm{mL}$, clone, 30-F11, BD Biosciences) and anti-CD31-FITC $(2.5 \mu \mathrm{g} / \mathrm{mL}$, clone, MEC 13.3; BioLegend, San Diego, CA, USA), both in PBS containing $2 \%$ FCS (15 min at room temperature). After washing, the cells were incubated with the dye 7AAD $(2.5 \mu \mathrm{g} / \mathrm{mL}$, BD Biosciences), a marker of dead cells, and analyzed by FACS. At least 100,000 cells/ sample were acquired with a FACS Fortessa system equipped FACSDiva software (BD Biosciences). Fluorescence minus-one (FMO) controls were used to gate marker-positive cells. Percentages of stained cells were determined using FlowJo software.

\subsection{Preparation of gold nanoparticles functionalized with NGR or isoDGR peptides and TNF}

Bifunctional gold nanoparticles bearing peptide-HSA and recombinant murine TNF were prepared by incubating colloidal gold ( $25 \mathrm{~nm}$; Aurion, The Netherlands) with a TNF solution pre-mixed with N1-, N3-, Iso1-, or Iso3-HSA with the $\mathrm{pH}$ of colloidal gold adjusted to 6.0 or 6.5 with $200 \mathrm{mM}$ sodium citrate buffer (100/1 volume ratio). In particular, two protein combination ratios were added to $1 \mathrm{~mL}$ of colloidal gold: a) $160 \mu \mathrm{g}$ of peptide-HSA and $16 \mu \mathrm{g}$ of TNF with gold $\mathrm{pH}$ adjusted to 6.0 and b) $160 \mu \mathrm{g}$ of peptide-HSA and $32 \mu \mathrm{g}$ of TNF with gold $\mathrm{pH}$ adjusted to 6.5. These ratios were chosen based on the results of preliminary studies performed to identify the concentrations that generate nanodrugs with optimal bifunctional properties and stability (Fig. S6 in the ESM). Mixtures were incubated for $1 \mathrm{~h}$ at room temperature under shaking. Then, $100 \mu \mathrm{L}$ of mPEG-SH solution $(15 \mu \mathrm{g} / \mathrm{mL}$ in water, $M_{\mathrm{W}}=20,000$, NANOCS) was added to the mixture and incubated for $15 \mathrm{~min}$ at room temperature. Finally, $28 \mu \mathrm{L}$ of a $10 \%$ HAS solution was added to saturate the gold nanoparticles. The mixtures were centrifuged twice $(12,000 \times g$ for $10 \mathrm{~min})$. The final products were resuspended with $5 \mathrm{mM}$ sodium citrate buffer, $\mathrm{pH}$ 6.0, containing $1 \%$ HSA to a final volume of $1 \mathrm{~mL}$ and stored at $-80{ }^{\circ} \mathrm{C}$. Nanoparticles bearing *HSA (lacking the targeting peptide) and TNF were also prepared $(\mathrm{Au} / \mathrm{TNF})$.

\subsection{Characterization of the physicochemical properties of nanodrugs}

The physicochemical properties of each nanodrug were characterized by UV-Vis spectrophotometry, DSL, TEM, and zeta-potential analyses as described in the ESM.

\subsection{Characterization of the functional properties of nanodrugs}

The number of bioactive TNF molecules loaded onto the nanoparticles was determined by a murine fibroblast LM cytotoxicity assay [25].

The binding of nanodrugs, before and after incubation at $37^{\circ} \mathrm{C}$ in $0.1 \mathrm{M}$ ammonium bicarbonate buffer, $\mathrm{pH} 8.5$, to sTNF-R2 and $\alpha \mathrm{v} \beta 3$ spotted on nitrocellulose filters was performed as described previously [24].

The binding of nanodrugs to microtiter plates coated with $\alpha \mathrm{v} \beta 3$ as was performed as follows. Human $\alpha \mathrm{v} \beta 3$ integrin solution and $0.5 \mu \mathrm{g} / \mathrm{mL}$ in PBS with $\mathrm{Ca}^{2+}$ and $\mathrm{Mg}^{2+}$ (DPBS; Cambrex, East Rutherford, NJ, USA) were added to 96-well microtiter plates (Falcon 3912, Becton Dickinson, $50 \mu \mathrm{L} /$ well) and incubated overnight at $4{ }^{\circ} \mathrm{C}$. All subsequent steps were carried out at room temperature. The plates were washed with DPBS and further incubated with DPBS containing 3\% BSA (200 $\mu \mathrm{L} /$ well; $1 \mathrm{~h})$. The plates were washed with $25 \mathrm{mM}$ Tris- $\mathrm{HCl}, 150 \mathrm{mM}$ sodium chloride, $1 \mathrm{mM}$ magnesium chloride, $1 \mathrm{mM}$ manganese chloride $(\mathrm{pH}$ 
7.4; washing solution), and filled with serial dilutions of the nanodrug solution $(50 \mu \mathrm{L} /$ well in washing solution containing 1\% BSA, binding buffer). After incubation for $2 \mathrm{~h}$, the plates were washed again and incubated with a rabbit polyclonal anti-TNF serum (IP301) diluted in binding buffer (1:1,000, $50 \mu \mathrm{L} /$ well, $1.5 \mathrm{~h}$ ) followed by a goat anti-rabbit peroxidase conjugate diluted in the same buffer $(1: 1,000,50 \mu \mathrm{L} /$ well, $1 \mathrm{~h}$ ). Bound peroxidase was detected by adding $o$-phenylenediamine chromogenic substrate $(70 \mu \mathrm{L} /$ well).

\subsection{Characterization of the pharmacological and toxicological properties of nanodrugs}

Studies in animal models were approved by the Ethical Committee of the San Raffaele Scientific Institute, and performed according to the prescribed guidelines. BALB/c female mice (6-7 weeks old; Charles River Laboratories, Calco, Italy) were challenged with subcutaneous injections in the left flank of $1.5 \times 10^{6}$ WEHI-164 cells. Mice were injected, i.v., with nanodrugs diluted with $0.9 \%$ sodium chloride containing $100 \mu \mathrm{g} / \mathrm{mL}$ HSA. Tumor growth was monitored by measuring tumor size with calipers. The tumor volume was estimated by calculating $r 1 \times r 2 \times r 3 \times 4 / 3 \pi$, where $r 1$ and $r 2$ are the longitudinal and lateral radii, and $r 3$ is the thickness of the tumor protruding from the surface of normal skin. Animals were sacrificed before tumors reached a diameter of 1.0 to $1.5 \mathrm{~cm}$. Tumor sizes are shown as means \pm SE.

\section{Acknowledgements}

This work was supported by grants from Worldwide Cancer Research (formerly known as AICR, GR:14-0066), Ministero della Salute of Italy (No. RF-2011-02350836) and Associazione Italiana Ricerca sul Cancro (No. AIRC IG-14338 and 9965).

We thank the ProMiFa (Protein Microsequencing Facility) at San Raffaele Scientific Institute for mass spectrometry analyses.

Electronic Supplementary Material: Supplementary material (regarding additional experimental methods and results) is available in the online version of this article at http://dx.doi.org/10.1007/s12274-016-1035-8.
Open Access: This article is distributed under the terms of the Creative Commons Attribution 4.0 International License (http://creativecommons.org/licenses/by/4.0/), which permits unrestricted use, distribution, and reproduction in any medium, provided you give appropriate credit to the original author(s) and the source, provide a link to the Creative Commons license, and indicate if changes were made.

\section{References}

[1] Curnis, F.; Sacchi, A.; Corti, A. Improving chemotherapeutic drug penetration in tumors by vascular targeting and barrier alteration. J. Clin. Invest. 2002, 110, 475-482.

[2] Curnis, F.; Sacchi, A.; Borgna, L.; Magni, F.; Gasparri, A.; Corti, A. Enhancement of tumor necrosis factor $\alpha$ antitumor immunotherapeutic properties by targeted delivery to aminopeptidase N (CD13). Nat. Biotechnol. 2000, 18, 1185-1190.

[3] Curnis, F.; Gasparri, A.; Sacchi, A.; Cattaneo, A.; Magni, F.; Corti, A. Targeted delivery of IFN $\gamma$ to tumor vessels uncouples antitumor from counterregulatory mechanisms. Cancer Res. 2005, 65, 2906-2913.

[4] Curnis, F.; Gasparri, A.; Sacchi, A.; Longhi, R.; Corti, A. Coupling tumor necrosis factor- $\alpha$ with $\alpha \mathrm{V}$ integrin ligands improves its antineoplastic activity. Cancer Res. 2004, 64, 565-571.

[5] Gregorc, V.; Zucali, P. A.; Santoro, A.; Ceresoli, G. L.; Citterio, G.; De Pas, T. M.; Zilembo, N.; De Vincenzo, F.; Simonelli, M.; Rossoni, G. et al. Phase II study of asparagineglycine-arginine-human tumor necrosis factor $\alpha$, a selective vascular targeting agent, in previously treated patients with malignant pleural mesothelioma. J. Clin. Oncol. 2010, 28, 2604-2611.

[6] Gregorc, V.; Citterio, G.; Vitali, G.; Spreafico, A.; Scifo, P.; Borri, A.; Donadoni, G.; Rossoni, G.; Corti, A.; CaligarisCappio, F. et al. Defining the optimal biological dose of NGR-hTNF, a selective vascular targeting agent, in advanced solid tumours. Eur. J. Cancer 2010, 46, 198-206.

[7] Corti, A.; Curnis, F.; Rossoni, G.; Marcucci, F.; Gregorc, V. Peptide-mediated targeting of cytokines to tumor vasculature: The NGR-hTNF example. BioDrugs 2013, 27, 591-603.

[8] Giljohann, D. A.; Seferos, D. S.; Daniel, W. L.; Massich, M. D.; Patel, P. C.; Mirkin, C. A. Gold nanoparticles for biology and medicine. Angew. Chem., Int. Ed. 2010, 49, 3280-3294.

[9] Cai, W. B.; Gao, T.; Hong, H.; Sun, J. T. Applications of gold nanoparticles in cancer nanotechnology. Nanotechnol. Sci. Appl. 2008, 1, 17-32. 
[10] Paciotti, G. F.; Myer, L.; Weinreich, D.; Goia, D.; Pavel, N.; McLaughlin, R. E.; Tamarkin, L. Colloidal gold: A novel nanoparticle vector for tumor directed drug delivery. Drug Deliv. 2004, 11, 169-183.

[11] Libutti, S. K.; Paciotti, G. F.; Byrnes, A. A.; Alexander, H. R., Jr.; Gannon, W. E.; Walker, M.; Seidel, G. D.; Yuldasheva, N.; Tamarkin, L. Phase I and pharmacokinetic studies of CYT-6091, a novel PEGylated colloidal gold-rhTNF nanomedicine. Clin. Cancer Res. 2010, 16, 6139-6149.

[12] Powell, A. C.; Paciotti, G. F.; Libutti, S. K. Colloidal gold: A novel nanoparticle for targeted cancer therapeutics. Methods Mol. Biol. 2010, 624, 375-384.

[13] Meng, J.; Yan, Z.; Wu, J.; Li, L.; Xue, X.; Li, M.; Li, W.; Hao, Q.; Wan, Y.; Qin, X. et al. High-yield expression, purification and characterization of tumor-targeted IFN- $\alpha 2 \mathrm{a}$. Cytotherapy 2007, 9, 60-68.

[14] Pasqualini, R.; Koivunen, E.; Kain, R.; Lahdenranta, J.; Sakamoto, M.; Stryhn, A.; Ashmun, R. A.; Shapiro, L. H.; Arap, W.; Ruoslahti, E. Aminopeptidase $\mathrm{N}$ is a receptor for tumor-homing peptides and a target for inhibiting angiogenesis. Cancer Res. 2000, 60, 722-727.

[15] Curnis, F.; Arrigoni, G.; Sacchi, A.; Fischetti, L.; Arap, W.; Pasqualini, R.; Corti, A. Differential binding of drugs containing the NGR motif to CD13 isoforms in tumor vessels, epithelia, and myeloid cells. Cancer Res. 2002, 62, 867-874.

[16] Di Matteo, P.; Arrigoni, G. L.; Alberici, L.; Corti, A.; GalloStampino, C.; Traversari, C.; Doglioni, C.; Rizzardi, G. P. Enhanced expression of CD13 in vessels of inflammatory and neoplastic tissues. J. Histochem. Cytochem. 2011, 59, 47-59.

[17] Curnis, F.; Longhi, R.; Crippa, L.; Cattaneo, A.; Dondossola, E.; Bachi, A.; Corti, A. Spontaneous formation of L-isoaspartate and gain of function in fibronectin. J. Biol. Chem. 2006, 281, 36466-36476.

[18] Curnis, F.; Cattaneo, A.; Longhi, R.; Sacchi, A.; Gasparri, A. M.; Pastorino, F.; Di Matteo, P.; Traversari, C.; Bachi, A.; Ponzoni, M. et al. Critical role of flanking residues in NGRto-isoDGR transition and CD13/integrin receptor switching. J. Biol. Chem. 2010, 285, 9114-9123.

[19] Curnis, F.; Sacchi, A.; Gasparri, A.; Longhi, R.; Bachi, A.; Doglioni, C.; Bordignon, C.; Traversari, C.; Rizzardi, G. P.; Corti, A. Isoaspartate-glycine-arginine: A new tumor vasculature-targeting motif. Cancer Res. 2008, 68, 70737082.

[20] Corti, A.; Curnis, F. Isoaspartate-dependent molecular switches for integrin-ligand recognition. J. Cell Sci. 2011, 124, $515-522$.
[21] Spitaleri, A.; Mari, S.; Curnis, F.; Traversari, C.; Longhi, R.; Bordignon, C.; Corti, A.; Rizzardi, G. P.; Musco, G. Structural basis for the interaction of isoDGR with the RGD-binding site of $\alpha v \beta 3$ integrin. J. Biol. Chem. 2008, 283, 19757-19768.

[22] Frank, A. O.; Otto, E.; Mas-Moruno, C.; Schiller, H. B.; Marinelli, L.; Cosconati, S.; Bochen, A.; Vossmeyer, D.; Zahn, G.; Stragies, R. et al. Conformational control of integrinsubtype selectivity in isoDGR peptide motifs: A biological switch. Angew. Chem., Int. Ed. 2010, 49, 9278-9281.

[23] Bochen, A.; Marelli, U. K.; Otto, E.; Pallarola, D.; MasMoruno, C.; Di Leva, F. S.; Boehm, H.; Spatz, J. P.; Novellino, E.; Kessler, H. et al. Biselectivity of isoDGR peptides for fibronectin binding integrin subtypes $\alpha 5 \beta 1$ and $\alpha v \beta 6$ : Conformational control through flanking amino acids. $J$. Med. Chem. 2013, 56, 1509-1519.

[24] Curnis, F.; Sacchi, A.; Longhi, R.; Colombo, B.; Gasparri, A.; Corti, A. IsoDGR-tagged albumin: A new $\alpha v \beta 3$ selective carrier for nanodrug delivery to tumors. Small 2013, 9, 673-678

[25] Curnis, F.; Corti, A. Production and characterization of recombinant human and murine TNF. Methods Mol. Med. 2004, 98, 9-22.

[26] Dondossola, E.; Rangel, R.; Guzman-Rojas, L.; Barbu, E. M.; Hosoya, H.; St John, L. S.; Molldrem, J. J.; Corti, A.; Sidman, R. L.; Arap, W. et al. CD13-positive bone marrowderived myeloid cells promote angiogenesis, tumor growth, and metastasis. Proc. Natl. Acad. Sci. USA 2013, 110, 20717-20722.

[27] Wong, A. H. M.; Zhou, D. X.; Rini, J. M. The X-ray crystal structure of human aminopeptidase $\mathrm{N}$ reveals a novel dimer and the basis for peptide processing. J. Biol. Chem. 2012, 287, 36804-36813.

[28] Merlot, A. M.; Kalinowski, D. S.; Richardson, D. R. Unraveling the mysteries of serum albumin-more than just a serum protein. Front. Physiol. 2014, 5, 299.

[29] Colombo, G.; Curnis, F.; De Mori, G. M. S.; Gasparri, A.; Longoni, C.; Sacchi, A.; Longhi, R.; Corti, A. Structureactivity relationships of linear and cyclic peptides containing the NGR tumor-homing motif. J. Biol. Chem. 2002, 277, 47891-47897.

[30] Liu, C.; Yang, Y.; Chen, L.; Lin, Y. L.; Li, F. A unified mechanism for aminopeptidase N-based tumor cell motility and tumor-homing therapy. J. Biol. Chem. 2014, 289, 34520-34529.

[31] Fields, G. B.; Noble, R. L. Solid phase peptide synthesis utilizing 9-fluorenylmethoxycarbonyl amino acids. Int. J. Pept. Protein Res. 1990, 35, 161-214. 